\title{
Intrathoracic fundoplication for reflux stricture associated with short oesophagus
}

\author{
K MOGHISSI \\ From the Humberside Cardiothoracic Surgical Centre, Castle Hill Hospital, Cottingham, North Humberside \\ ABSTRACT Intrathoracic fundoplication was carried out in 45 patients with reflux stricture \\ associated with a short oesophagus after the stricture had been fully dilated at operation. There \\ were two deaths in hospital $(4 \cdot 4 \%)$. The follow-up extended from one to 10 years. Two patients \\ required dilatation and four others had symptoms of nausea and fullness, all for up to six months. \\ Thirty-seven patients remained symptom free. No patient required further surgery. The procedure \\ is recommended as a conservative surgical method for patients with reflux stricture associated with \\ shortening of the oesophagus.
}

Acquired short oesophagus is a fixed elevation of the gastro-oesophageal junction associated with sliding hiatal hernia and reflux oesophagitis. When combined with a stricture it presents a challenging therapeutic problem to the surgeon, particularly if the patient is elderly and in poor general condition.

Dilatation of the stricture alone provides no permanent solution for these patients, since the causative reflux is not controlled. In addition, there is an ever-increasing risk of perforation of the oesophagus when tight strictures are forcibly dilated; and frequent visits to the hospital interfere with the patient's quality of life.

In the past these considerations and the difficulty of dilating some strictures have led to radical treatment by resection of the stricture and reconstruction of the oesophagus, ${ }^{1-5}$ but there is now a tendency to use conservative surgical methods whenever possible. ${ }^{6-9}$ These are based on perioperative dilatation of the stricture combined with an antireflux repair positioned below the diaphragm. In the presence of oesophageal shortening, however, this may not be possible. To deal with this problem Collis designed a gastroplasty to lengthen the oesophagus ${ }^{10}$ and more recently this has been combined with a Belsey ${ }^{11}$ or Nissen ${ }^{12}$ procedure for the treatment of these patients.

For the past 12 years we have treated cases of short oesophagus with stricture by intraoperative dilatation and an intrathoracic Nissen fundoplication. In this paper we describe the technique and report on our experience and the long-term results.

Address for reprint requests: Mr K Moghissi, Humberside Cardiothoracic Surgical Centre, Castle Hill Hospital, Cottingham, North Humberside.

\section{Patients}

From September 1970 to September 1980245 patients with reflux stricture of the oesophagus were treated by operation (table 1). In 96 patients the stricture was associated with a short oesophagus and 51 of these underwent excision of the stricture and reconstruction of the upper alimentary tract using stomach, $\stackrel{\mathbb{Q}}{\Omega}$ jejunum, or colon. In the remaining 45 patients a $\overrightarrow{\vec{O}}$ conservative operation was performed. The latter 3 group of patients is the subject of this paper. The age and sex of the patients and the distribution and duration of their symptoms are shown in table 2 . All suffered from dysphagia, which was almost total in 17 을 and less severe in the remaining 28 patients.

Every patient had had symptoms of heartburn, reflux, and pain on deglutition, recorded over periods of one to 20 years (mean 5.6 years). Haematemesis $ᄋ$ was recorded in eight patients and loss of more than $5 \mathrm{~kg}$ in weight in 13 patients. Every patient had 응 undergone oesophageal dilatation at least three times $>$ before operation. Eight patients had had repeated dilatation elsewhere for two to 10 years and were $\bar{N}$ referred to our unit when the method had failed. $\%$ Three others had been practising daily self-bouginage $\tilde{O}$ for a period of two to four years. Four patients had $\underset{\mathrm{C}}{\mathcal{W}}$ previously had repair of a hiatal hernia.

The barium-swallow examination showed $a_{\odot}$ stricture and hiatal hernia in every case. At $\frac{\mathscr{C}}{\mathbb{C}}$ oesophagoscopy the level of the stricture was $\stackrel{\oplus}{\rightarrow}$ carefully recorded. Biopsy specimens were taken 0 above, at, and when possible below the stricture and $\bar{O}$ an attempt at dilatation of the stricture was made. $\stackrel{\mathbb{D}}{\Omega}$ The stricture was classed as tight when it was rigid and $\mathbb{\otimes}$ unyielding to the passage of bougies, moderately 
Table 1 Surgical treatment of reflux stricture of the oesophagus in 245 patients

\begin{tabular}{llrr}
\hline Category & Type of operation & No & Total \\
\hline Stricture with short oesophagus & Radical (resection and reconstruction) & 51 \\
Stricture without short oesophagus & Conservative (dilatation and intrathoracic fundoplication) & 45 \\
Total & Radical (resection and reconstruction) & 96 \\
38 \\
Conservative (dilatation and repair of hiatal hernia) & $111\}$ & 149 \\
& & 245 \\
\hline
\end{tabular}

Table 2 Data on patients with stricture and short oesophagus

\begin{tabular}{lllll}
\hline & $\begin{array}{l}\text { Age range (mean) } \\
(y)\end{array}$ & Sex $(F: M)$ & Duration of symptoms (y) & Strictures \\
\hline Conservative surgery & $\begin{array}{l}42-78 \\
(66 \cdot 9)\end{array}$ & $1 \cdot 4: 1$ & $1-20$ & Dilatable at operation \\
Radical surgery & $22-85$ & $1 \cdot 3: 1$ & $(5 \cdot 6)$ & Undilatable at operation \\
& $(67 \cdot 8)$ & & $(6 \cdot 8)$ & \\
\hline
\end{tabular}

tight when it was resistant but allowed the introduction of bougies of increasing diameters, and soft when it offered little resistance to the passage of bougies and could easily be dilated. Of the 45 patients in this series, 14 had tight, 22 moderately tight, and nine soft strictures. The approximate overall length of the oesophagus of each subject was recorded, the technique of d'Abreu et al $^{13}$ being used. From the endoscopic level of the stricture, the findings of the barium-swallow examination, and the length of the oesophagus the distance of the stricture from the arch of the aorta and the hiatus was determined.

\section{Operative technique}

The oesophagus and the stomach were exposed through a left posterolateral thoracotomy, with a circumferential incision in the diaphragm. The oesophagus was fully mobilised by sharp and blunt dissection of the fibrotic tissue in the mediastinum. The oesophageal hiatus was cleared of fibro-fatty tissue and the phreno-oesophageal ligament defined and dissected free from the hiatus. The fundus and a variable portion of the body of the stomach were mobilised by ligating and dividing the relevant gastrosplenic, gastrocolic, and gastrohepatic omenta with their blood vessels. The oesophageal hiatus was then enlarged so that it allowed the delivery of the fundus and part of the body of the stomach into the chest.

The stricture was first explored digitally through a gastrotomy. Transgastric dilatation, at times forcible, was then carried out by the retrograde passage of Hegar bougies of increasing diameter ( $\leqslant 22-24 \mathrm{~mm})$, which were introduced with one hand and guided with the other around the oesophagus. After the dilatation the gastric incision was closed and a Nissen fundoplication was carried out with three to five stitches, which not only plicated the fundus but also the juxtafundal portion of the stomach, particularly in cases where the shortening was pronounced.

In this way an elongated plication without much bulging was obtained in cases with a very short oesophagus. The phreno-oesophageal ligament was included in the highest of the "wrap" stitches and excessive narrowing of the oesophagus was avoided by maintenance of a groove between the plication and the oesophagus that allowed the tip of the little finger. The upper border of the fundoplication was then sutured with a few interrupted stitches to the oesophagus.

Because of the shortening the lower oesophagus wrapped by the fundoplication could not be returned beneath the diaphragm. It was therefore left in the posterior mediastinum, where it was easily accommodated. Finally, the stomach was anchored to the borders of the hiatus to prevent herniation alongside it. Figures 1 and 2 show the results of barium studies in two patients and the radiological appearance of the intrathoracic fundoplication.

\section{Results}

All patients had a barium-swallow examination 10-12 days after operation, by which time they were eating food of normal consistency. Oesophagoscopy was carried out only if a patient had residual dysphagia or was known to have had a preoperative oesophageal ulcer. Every surviving patient was followed up in the outpatient clinic by a member of the surgical team at regular intervals. Follow-up extends from one to four years for 17 patients and from five to 10 years for 26 patients. 

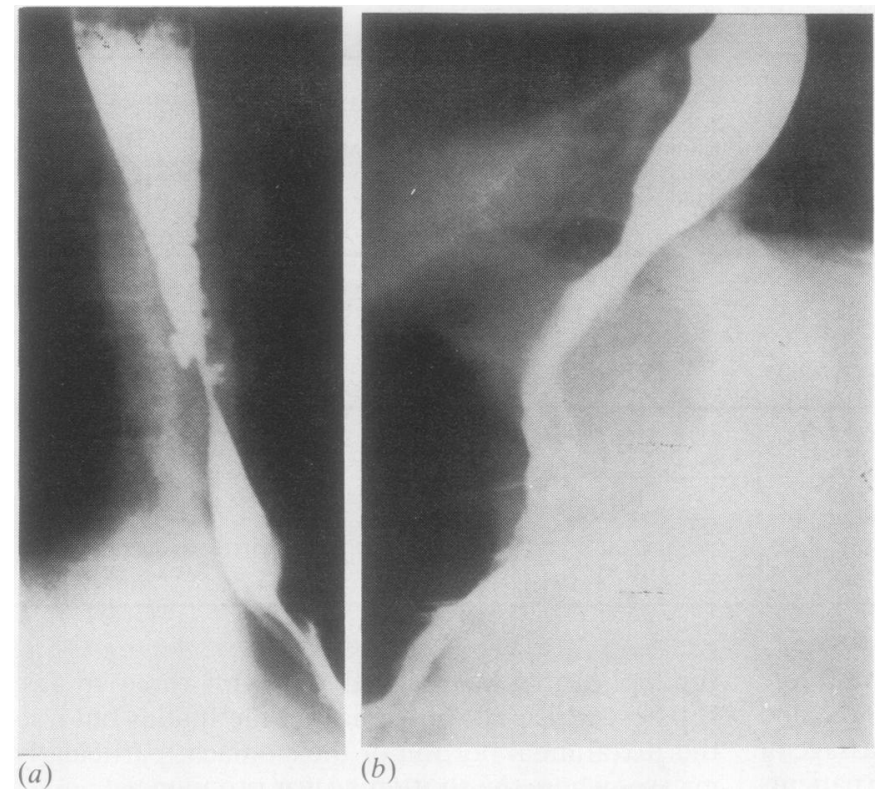

Fig 1 Radiographs of barium swallows in the same patient (a) before and (b) after intrathoracic Nissen fundoplication.

Table 3 Results of surgery in patients with stricture and short oesophagus

\begin{tabular}{llll}
\hline Type of surgery & $\begin{array}{l}\text { No }(\%) \text { of } \\
\text { deaths }\end{array}$ & $\begin{array}{l}\text { No (\%) having } \\
\text { postoperative } \\
\text { dilatation }\end{array}$ & $\begin{array}{l}\text { No(\%) having } \\
\text { postoperative } \\
\text { symptoms }\end{array}$ \\
\hline $\begin{array}{l}\text { Conservative } \\
\text { surgery (n=45) }\end{array}$ & $2(4 \cdot 4)$ & $2(4 \cdot 4)$ & $4(8 \cdot 8)$ \\
$\begin{array}{l}\text { Radical surgery } \\
(\mathrm{n}=51)\end{array}$ & $5(9 \cdot 8)$ & $3(5 \cdot 8)$ & $6(11 \cdot 6)$ \\
\hline
\end{tabular}

operation for the removal of large pieces of impacted meat. Another patient had residual dysphagia음 requiring dilatation on two occasions during the first $\stackrel{0}{x}$ six months after surgery. Four other patients complained of a feeling of fullness and nausea for up to six months after their operations. They were all treated successfully medically. Thirty-seven $(86 \%)$ of the surviving 43 patients remained completely symptom응 free after their operations and no patient has required $\bar{D}$ further operative treatment.

\section{Discussion}

In response to gastro-oesophageal reflux an N inflammatory reaction develops in the oesophagus and leads to stricture formation at thee squamocolumnar mucosal junction. ${ }^{14}$ In chronic cases the inflammatory scarring and fibrosis are not? $\stackrel{?}{+}$ solely confined to the mucosa but affect the whole $\square$ thickness of the oesophagus as well as the웅 perioesophageal mediastinal tissues. In some patients $\varrho$ the stricture and the oesophagogastric junction $\stackrel{\mathbb{Q}}{\mathscr{Q}}$ ascend from the hiatus, accounting for the
Fig 2 Radiographs of barium swallows in another patient (a) before and (b) after intrathoracic Nissen fundoplication.

The results of treatment are shown in table 3. Two patients died in hospital (mortality $4.4 \%$ ), one from myocardial infarction on the second postoperative day and the other from pulmonary infection two days after operation. One patient required oesophagoscopy and dilatation 10 days after 
shortening. The concept of acquired short oesophagus is not acknowledged by all. ${ }^{75}$ Previous anatomical studies in our department, however, ${ }^{16}$ leave no doubt of its existence and support many other authors' acceptance of acquired short oesophagus as an entity. ${ }^{11121417}$

The aim of treatment in all obstructive lesions of the oesophagus is to restore normal swallowing and to prevent a recurrence of the obstruction. There is now considerable evidence to suggest that in many cases of reflux stricture this aim can be achieved by conservative surgical methods without the need for oesophageal resection. ${ }^{6-9}$ Such methods, however, require the provision of an antireflux mechanism, which can be difficult in cases of stricture with short oesophagus. Although the Collis gastroplasty ${ }^{17}$ achieves an effective lengthening of the oesophagus, in itself it appears to be an insufficient barrier against reflux.

Patients with stricture and short oesophagus treated by gastroplasty alone may therefore be at risk of recurrence of the stricture. Coupled with an antireflux procedure, however, gastroplasty can be expected to achieve successful results. This has been the basis of the so-called Collis-Belsey and CollisNissen operations, ${ }^{11}{ }^{12}$ in which a Belsey or Nissen hiatal hernia repair is added to the gastroplasty. The rational basis of our method consists of full dilatation combined with an intrathoracic Nissen fundoplication.

There is now general agreement that the Nissen fundoplication ${ }^{18}$ controls gastro-oesophageal reflux. The antireflux property of fundoplication depends on its ability to act as a flutter valve rather than any action on the sphincter itself. ${ }^{19}{ }^{20}$ It therefore follows that the position of the fundoplication (whether above or below the diaphragm) should not affect its effectiveness as an antireflux mechanism. This is borne out by our experience and that of Milstein, ${ }^{21}$ who has used intrathoracic fundoplication combined with oesophagoplasty to treat severe oesophageal strictures.

Table 1 indicates some interesting points. Firstly, in this relatively large group of patients undergoing surgery for reflux stricture $96(39 \%)$ had a short oesophagus by our definition, which may be considered as a high percentage of cases. This, however, has to be viewed in the context of the fact that, firstly, only patients with established strictures have been considered in this series and those patients with a stricture who were treated by simple hiatal hernia repair without the intraoperative dilatation of the stricture are not included; and, secondly, those patients (about nine to $10 \%$ of our cases) who did not undergo surgery are not considered. Table 1 also shows that most of our patients with a stricture not associated with oesophageal shortening could be treated conservatively. For those patients who had a stricture associated with short oesophagus the reverse was true. This is presumably the result of more inflammation of the oesophagus in the latter cases. Most of the patients treated conservatively had a tight or moderately tight stricture, but all strictures could be dilated at operation.

Table 2 shows that there were no significant differences in age, sex, or duration of symptoms between those patients with short oesophagus requiring conservative and resectional surgery. Dilatation could not be achieved satisfactorily, however, in the patients who had to be treated by radical surgery.

The results of conservative surgery in our patients with short oesophagus (table 3 ) show that all but two patients who survived the operation needed no further dilatation, and that in these two dilatation was required early after surgery, which may not be considered as recurrence of the stricture. All other patients have continued to swallow food of a normal consistency without any difficulty and have remained symptom free.

This clinical experience therefore confirms that intrathoracic fundoplication does prevent the recurrence of the stricture, and that when combined with intraoperative dilatation it provides effective surgical treatment for reflux strictures associated with hiatal hernia and short oesophagus.

Encouraged by our earlier results with intrathoracic fundoplication we now find that an increasing number of patients with a stricture and short oesophagus can be offered a conservative operation, provided that the stricture can be effectively dilated at operation. In our series of patients the results of intrathoracic fundoplication are satisfactory and at least as good as the outcome in patients treated by resectional surgery.

I am grateful to Mrs M Dench for her help in the preparation of this paper and Miss L Chandler for secretarial assistance.

\section{References}

Allison PR, Da Silva LT. The roux loop. Br J Surg 1953;41:173-80.

2 Ellis FH, Andersen HA, Clagett OT. Surgical management of the complications of reflux oesophagitis. Arch Surg 1956;73:578-89.

${ }^{3}$ Belsey R. Reconstruction of the oesophagus with left colon. J Thorac Cardiovasc Surg 1965;49:33-55.

+ Gavriliu D. L'État actuel du procédés de reconstruction de l'oesophage par tube gastric. 1138 malades opérés. Ann Chir 1965;19:219-24. 
${ }^{s}$ Brain RHF. The place for jejunal transplantation in the treatment of simple strictures of the oesophagus. Ann $R$ Coll Surg Engl 1967;40:100-18.

${ }^{6}$ Hayward J. The treatment of fibrous stricture of the oesophagus associated with hiatal hernia. Thorax 1961;16:45-55.

${ }^{7}$ Hill LD, Gelfand M, Bauermeister D. Simplified management of reflux oesophagitis with stricture. Ann Surg 1970;172:638-51.

${ }^{8}$ Herrington LL, Wright RS, Edwards WH, et al. Conservative surgical treatment of reflux oesophagitis and oesophageal stricture. Ann Surg 1975;181:552-66.

${ }^{9}$ Moghissi K. Conservative surgery in reflux stricture of the oesophagus associated with hiatal hernia. $\mathrm{Br} J$ Surg 1979;66:221-5.

${ }^{10}$ Collis J. An operation for hiatal hernia with short oesophagus. Thorax 1957;12:181-8.

"Pearson FG, Langer B, Henderson MB. Gastroplasty and Belsey hiatal hernia repair, an operation for the management of peptic stricture with acquired short oesophagus. J Thorac Cardiovasc Surg 1971;61:50-63.

${ }^{12}$ Ellis FH, Leonardi HK, Dabuzhsky L, Crozier RE. Surgery for short oesophagus with stricture: an experimental and clinical manometric study. Ann Surg
1978; 188:341-50.

${ }^{13}$ D'Abreu A, Collis JL, Clarke DB. A practice of thoracic surgery. 3rd edition. London: Edward Arnold, 1971:475.

${ }^{14}$ Allison PR. Peptic oesophagitis and oesophageal stricture. Lancet 1970;ii:199-202.

${ }^{15}$ Belsey R. Discussion. J Thorac Cardiovasc Surg $\stackrel{\mathbb{D}}{\varnothing}$ 1977;74:734.

${ }^{16}$ Moghissi K. Stenose haute de l'oesophage thoracique et leur traitement chirurgical. Chirurgie 1980;106:711-8.

${ }^{17}$ Collis JL. Gastroplasty. Thorax 1961;16:197-206.

${ }^{18}$ Nissen R. Eine einfache Operation zur Beeinflussung des Reflux Oesophagitis. Schweiz Med Wochenschr 1956;86:590-2.

${ }^{19}$ Ellis FH, Garbedian M, Gregg JA. Fundoplication for $\grave{D}_{\infty}$ gastro-oesophageal reflux: a comparison of preoperative and early post-operative manometric $\dot{\omega}_{-}$ findings. Chest 1972;62:142-5.

${ }^{20}$ Ellis FH, El-Kurd MFA, Gibb SP. The effect of $\frac{\text { ? }}{2}$ fundoplication on the lower oesophageal sphincter. Surg Gynec Obstet 1976;143:1-5.

${ }^{21}$ Milstein BB. An operation for the treatment of intractable peptic stricture of the oesophagus. Israel $J \stackrel{\text { गे }}{\stackrel{2}{2}}$ Med Sci 1975;2:281-6. 